\title{
Mathematical modeling in CAD elements vehicles food and chemical industry
}

\section{Pavlo Shvets, Alla Toropenko, Ievgene Naumenko, Husain Walid Sher}

\author{
Odesa National Polytechnical University, Odesa, Ukraine
}

Keywords:

CAD

Stress

Deformation

Circular plate

Gauss

Function

Article history:

Received 22.10.2016

Received in revised

form 23.12.2016

Accepted 30.12.2016

\section{Corresponding \\ author:}

Toropenko Alla

E-mail:

alla.androsyk@

gmail.com

DOI: $10.24263 / 2310-$

1008-2016-4-2-15

\section{Abstract}

Introduction. The work is devoted to improving the quality of computer-aided design of food and chemical equipment by reducing the weight of their parts while maintaining the reliability of the machines as a whole.

Materials and methods. The stress-strain state of round shells operating under distributed load is investigated. In apparatuses of increased pressure, such parts are the bottoms. The calculations use mathematical methods that use the functions of Gauss, Whittaker and Cumera. For such calculations, the Maple 13 program was used.

Results and discussion. It is established that round plates of constant thickness turn out to be constructively irrational. In this connection, the paper proposes a transition to designing round plates of variable thickness and a method for designing such plates is being developed. An analytical method for determining the stress-strain state of plateshaped parts of circular shape and variable thickness during bending is developed, which allows obtaining a solution in the most convenient form for analysis (in the form of formulas). The boundary of the circular plate is a circle, so the polar coordinate system is used for calculations. The two functions of Whitaker of the first and second kind were involved in the denouement. Comparing the parameters in the Whitaker function and in Kummer functions, we defined a new form for the eigenfunctions. Checking the equivalence of the transition to Kummer functions is performed in the program Maple 13. Full coincidence of the graphs of the eigenfunctions indicates the correctness of the replacement. The functions of Kummer and Whittaker belong to the class of degenerate hypergeometric functions, they are used to construct solutions in certain problems of physics, astronomy, and mechanics.

Conclusions. A method is proposed for designing rational diametrical cross-sections of machine elements and apparatus, which have the form of circular plates. 


\section{Introduction}

One of the most important technical characteristics of the machines and devices is their weight. When developing new and improving existing designs, designers are always seeking to reduce material consumption and reduce the weight of products. The best known technical solutions and recommendations for the design details dimensional structures rods. Beams - core operating bending - made from standard rolled sections (beams, channels, rails, etc.), In which the material is largely removed from the neutral axis, thus providing multiple increase in axial moment of inertia, strength and rigidity. Gear - rods working in torsion - in many cases, are shaped pipes and compared with a solid crosssection of the same area of strength and stiffness characteristics increase several times.

Similar advantages are achieved by weight in the disc-shaped parts. Gears, pulleys, flywheels, wheel vehicles in the middle of the drive are thin, often facilitated holes or spokes (wheel bike). Such designs have less mass and, hence, lower cost, high competitiveness.

Development of machines, apparatus and their parts with a minimum weight is more difficult to design because it requires unconditional providing strength with increasing complexity of such schemes calculated essentially heterogeneous products.

\section{Analytical review}

The quality of the machines of the same designation estimate the specific gravity, defined as the quotient of weight $G$ on the main parameter. For example, energy and others. machines such parameter is the value

where $N$ - the power unit.

$$
g=\frac{G}{N}
$$

It is a composite index that takes into account the degree of structural perfection and use of light alloys and non-metallic materials. For example, modern tanks, the Figure is: Leclerc (France) $\mathrm{g}=50 \mathrm{~kg} / \mathrm{kW}, \mathrm{T}-84$ (Ukraine) $\mathrm{g}=52 \mathrm{~kg} / \mathrm{kW}$ M1A2 Abrams (USA) $\mathrm{g}=$ $56,8 \mathrm{~kg} / \mathrm{kW}$, T90S (Russia ) $\mathrm{g}=63,2 \mathrm{~kg} / \mathrm{kW}$.

In the transport engineering quality estimate dimensionless ratio $g_{1}$ weight design to the mass of the payload. For sea transport $\mathrm{g}_{1}=20-30$, Track $\mathrm{g}_{1}=10-20$, for automotive $\mathrm{g}_{1}=$ $3-5$, for aircraft $\mathrm{g}_{1}=1,2-2,5$.

Feature of machines and devices food and chemical industries have a huge range of types and dribnoseriynist, and some of them are available in single copies. The main indicator of the quality of vehicles and machinery in the chemical industry is the reliability of their work, ie property vehicles or machines perform their functions, while maintaining their operational performance to set limits for the required period of time or the required operating time. In this regard, designers often dealing with reduction of material last. The textbook [5], for example, states: "The current level of chemical production requires designing and manufacturing machines and equipment quality. Other possible with the optimal combination of these technical and economic parameters: maximum working volume, high productivity simplicity, reliability and safety at work, energy and the lowest metal content».

But there are exceptions: nowadays to store liquid materials received widespread use of vertical cylindrical shell with variable speed wall thickness that decreases in height. For 


\section{- Processes and Equipment of Food Productions}

small volume tanks, $10-20 \mathrm{~m}^{3}$, saving material goes low, $8-10 \%$, but the order volume of $10,000 \mathrm{~m}^{3}-35 \%$ compared to the reservoir wall with constant thickness [6].

A similar result can be obtained also in the design of machine parts and devices in the shape of plates, including a circular shape (covers, bottoms, aperture devices, etc.). In a circular plate of radius $R$, which is bent uniformly distributed load $q$, bending moment turns radially distributed very unevenly. When joints leaning on the circuit in the center of a plate having radial and circumferential moments of equal magnitude

$$
M_{r}(0)=M_{t}(0)=0,208 q r^{2},
$$

whereas in circuit

$$
M_{r}(R)=0 ; M_{t}(R)=0,0835 q r^{2} .
$$

The value of bending moments from the center to the periphery of the circular plate pivotally obpertoyi, as we see, reduced by 2,5 times.

For the same plate with rigid circuit pattern of change of bending moment is different, but also essential. In the center of bending moments

$$
M_{r}(0)=M_{t}(0)=0,0833 q r^{2},
$$

and the circuit

$$
M_{r}(R)=-0,125 q r^{2} ; M_{t}(R)=-0,042 q r^{2} .
$$

Here is larger by 1.5 times (in absolute value) is bending moment on the circuit. Besides the two points changes sign, so a value of radial coordinate $r=(0,6 R \ldots 0,8 R)$ bending moment is zero at all [1].

From the above analysis shows that the round plate thickness are constant constructive irrational. In this regard, in this work the transition to designing circular plates of variable thickness design method is developed and such plates.

The issue of circular plates with thickness variation studied by some authors find solutions using power series, methods or finite element mesh. Overview on the subject is in monographs $[4,8]$. Solutions to some problems such plates are shown in tabular form in the directory. [1] This paper developed an analytical method for determining the stress-strain state of the plate parts round shape and variable thickness when bent, which provides a solution to the most convenient for the analysis of closed form (a formula).

\section{Purpose of the work}

The aim is to improve the quality of machine parts rivnonapruzhenyh design by reducing the weight of the respective components while maintaining their reliability through the development and implementation of mathematical models of circular plates of variable thickness, which is under transverse load.

To achieve this, the work was made and solved the following problems:

- Analytical review of the conditions of establishment and operation rivnonapruzhenyh machine parts and methods of computer-aided design;

- the basic characteristics of the strain of round plates, used for their mathematical modeling;

- the mathematical model of bending circular plate variable thickness Gaussian function given in the form of second order differential equation with variable coefficients; 


\section{- Processes and Equipment of Food Productions -}

- performed computer simulations circular plate of variable thickness of the rocker bearing on the external circuit and the main characteristics of the stress state of circular plates of variable thickness bending.

\section{Result and discussion}

\section{Characteristics of circular plates deformation}

The action of transverse load $q(r)$ on a round plate, mounted symmetrically in the district towards the central axis $z$, moving its middle surface (deflection) is also a function of radial coordinate only, $w(r)$. Such deformation is called axisymmetrical. For plate thickness $h(r)$ will only variable in the radial direction deflection $w(r)$ and remain axisymmetric stress state [12-14].

The frontier is a circular plate circumference, so the calculations used polar coordinate system. And for the aggregate points located at the same distance $r$ from the center of the plate curvature radius curved middle surface in the radial direction and the district will be different, according $\rho_{1}$ and $\rho_{2}$, Figure 1 .

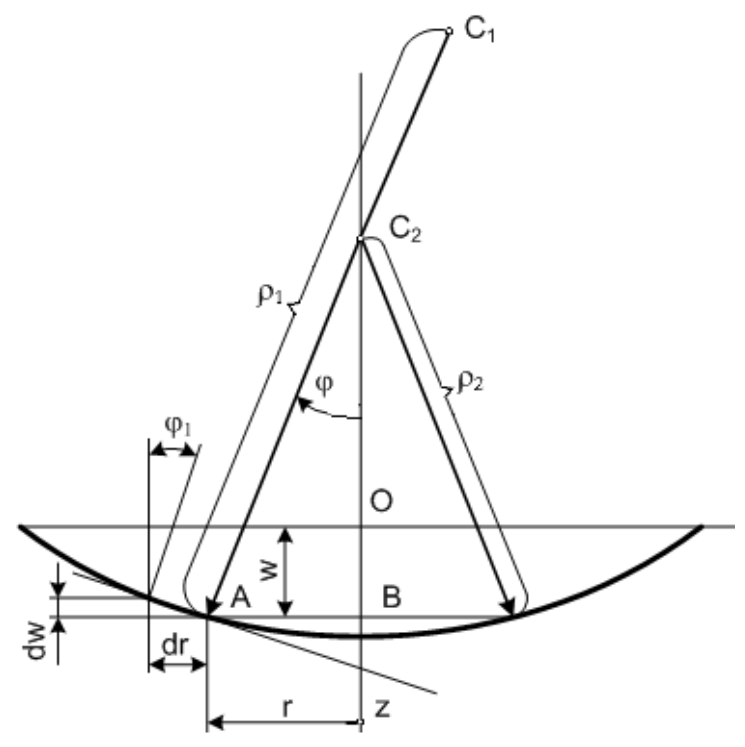

Figure 1. Geometric features curved surface of a circular plate

The angle of the bent middle surface $\varphi(r)$ associated with the deflection $w(r)$ and the radius of curvature of dependency [8]

$$
\frac{1}{\rho_{1}}=k_{1}=\frac{d \phi}{d r}=-\frac{d^{2} w}{d r^{2}},
$$




$$
\frac{1}{\rho_{2}}=k_{2}=\frac{\phi}{r}=-\frac{1}{r} \cdot \frac{d w}{d r},
$$

where $k_{1}$ i $k_{2}$ - curvature of the curved middle surface in the radial and district areas.

Plate thickness $h(r)$ and the load $q(r)$ in the district feel the same direction as the bent middle surface shape is symmetrical axis $z$. Differential equations of axisymmetric bending of circular plates of variable thickness $h(r)$ for determining the deflection $w(r)$ is the fourth order [1]

$$
D \nabla^{2} \nabla^{2} w+\frac{d D}{d r}\left(2 \frac{d^{3} w}{d r^{3}}+\frac{2+\mu}{r} \frac{d^{2} w}{d r^{2}}-\frac{d w}{r^{2} d r}\right)+\frac{d^{2} D}{d r^{2}}\left(\frac{d^{2} w}{d r^{2}}+\frac{\mu}{r} \frac{d w}{d r}\right)=q(r),
$$

where variable stiffness cylindrical plate

$$
D(r)=\frac{E h^{3}(r)}{12\left(1-\mu^{2}\right)} .
$$

Here, E, $\mu$ - modulus and Poisson's ratio - the mechanical characteristics of the material plates are considered constants.

In the formula (3) differential Laplace operator

$$
\nabla^{2} w=\frac{d^{2} w}{d r^{2}}+\frac{1}{r} \cdot \frac{d w}{d r} .
$$

We believe that $q>0$ and $w>0$ if they are directed downwards.

\section{The differential equation of bending circular plate variable thickness given Gaussian function}

Radially variable thickness $r$ describe addiction, called the Gaussian function

$$
h(r)=h_{0} \exp \left(\frac{n r^{2}}{6 R^{2}}\right)
$$

where $R$-radius contour plate, $h_{0}-$ its thickness at the center, $n$ - parameter.

Description form radial crossing plates expression (6) is quite common, because this formula simulates the plate in which the thickness or increases from the center to the periphery (for $n>0$ ) or decreases (when $n<0$ ), and the parameter $n$ determines intensity changes thickness.

To calculate bending moments to find deflections of the fourth order equation (3) is not necessary, since these factors can be expressed in terms of angles in the formula (2):

$$
\phi(r)=-\frac{d w}{d r} .
$$




\section{- Processes and Equipment of Food Productions -}

Substitution in equation (3) deflections at angles according to the dependence (7) allows the lower order differential equation (3) to the second:

$$
D \frac{d}{d r}\left(\frac{d \phi}{d r}+\frac{\phi}{r}\right)+\frac{d D}{d r}\left(\frac{d \phi}{d r}+\mu \frac{\phi}{r}\right)=-\frac{1}{r} \int_{0}^{r} q(r) r d r=-\frac{q_{0} r}{2}
$$

Here the importance of the right to a received load $q_{0}$, evenly distributed across the surface of the plate.

If the solution of equation (8) is received, the deflection can be found by integration of the expression (7): $w(r)=-\int \phi(r) d r+C_{0}$. Continuous integration $C_{0}$ determined by the condition fixing plate.

In (8) to the dimensionless coordinates, replacing $r=x \cdot R$. The formulas for cylindrical rigidity (4) and its derivative thickness (6) have the form

$$
D=\frac{E h_{0}^{3}}{12\left(1-\mu^{2}\right)} \exp \left(\frac{n x^{2}}{2}\right) ; \quad \frac{d D}{d r}=\frac{E h_{0}^{3}}{12\left(1-\mu^{2}\right)} \frac{n x}{R} \exp \left(\frac{n x^{2}}{2}\right) .
$$

After substituting (9) into (8) and some transformations we obtain the differential equation of 2 nd order with variable coefficients

$$
\frac{d^{2} \phi}{d x^{2}}+\left(\frac{1}{x}+n x\right) \frac{d \phi}{d x}-\left(\frac{1}{x^{2}}-\mu n\right) \phi=-\frac{1}{r} \int_{0}^{r} q(\rho) \rho d \rho=-\bar{p} x \exp \left(-\frac{n x^{2}}{2}\right),
$$

where the dimensionless factor

$$
\bar{p}=6\left(1-\mu^{2}\right) \frac{q_{0}}{E} \cdot \frac{R^{3}}{h_{0}^{3}} .
$$

Get the solution of equations with variable coefficients, which is also (10), using elementary functions often can not $[1,2]$. So turn to mathematical program Maple 13, where there is a corresponding mathematical apparatus. Using this program replaced the designation function $\varphi(\mathrm{x}) \rightarrow \mathrm{y}(\mathrm{x})$, recorded respective teams and obtained the following results.

$$
\begin{aligned}
& \frac{d^{2}}{d x^{2}} y(x)+\left(\frac{1}{x}+n \cdot x\right) \cdot\left(\frac{d}{d x} y(x)\right)-\left(\frac{1}{x^{2}}-m \cdot n\right) \cdot y(x)+p \cdot x \cdot e^{-\frac{1}{2} n x^{2}} \frac{d^{2}}{d x^{2}} y(x)+ \\
& +\left(\frac{1}{x}+n \cdot x\right) \cdot\left(\frac{d}{d x} y(x)\right)-\left(\frac{1}{x^{2}}-m \cdot n\right) \cdot y(x)+p \cdot x \cdot e^{-\frac{1}{2} n x^{2}}
\end{aligned}
$$


$y(x)=\frac{e^{-\frac{1}{4} n x^{2}} \text { Whittaker } M\left(\frac{1}{2} m-\frac{1}{2}, \frac{1}{2}, \frac{1}{2} n x^{2}\right)-C 1}{x}+y(x)=$

$=\frac{e^{-\frac{1}{4} n x^{2}} \text { Whittaker } M\left(\frac{1}{2} m-\frac{1}{2}, \frac{1}{2}, \frac{1}{2} n x^{2}\right)-C 1}{x}+\frac{e^{-\frac{1}{4} n x^{2}} \text { Whittaker } W\left(\frac{1}{2} m-\frac{1}{2}, \frac{1}{2}, \frac{1}{2} n x^{2}\right)-C 2}{x}-$

$-\frac{p \cdot x \cdot e^{-\frac{1}{2} n x^{2}}}{n(-3+m)}+\frac{e^{-\frac{1}{4} n x^{2}} \text { Whittaker } W\left(\frac{1}{2} m-\frac{1}{2}, \frac{1}{2}, \frac{1}{2} n x^{2}\right)-C 2}{x}-\frac{p \cdot x \cdot e^{-\frac{1}{2} n x^{2}}}{n(-3+m)}$.

This solution involved two functions Uittekera (FU) first and second kind, also used in [9]. For these functions in mathematical notation used literature $M_{k, s}(z)$ i $W_{k, s}(z)$, [6]. In this case, the parameters $k=0,5(\mu-1), s=0,5, z=0,5 n x^{2}$ and the angle defined by the formula

$$
\phi(x)=x^{-1} \exp \left(-\frac{n x^{2}}{4}\right)\left[C_{1} M_{\frac{\mu-1}{2}, \frac{1}{2}}\left(\frac{n x^{2}}{2}\right)+C_{2} W_{\frac{\mu-1}{2}, \frac{1}{2}}\left(\frac{n x^{2}}{2}\right)\right]+\frac{\bar{p} x}{(3-\mu) n} \exp \left(-\frac{n x^{2}}{2}\right) .
$$

It features its own differential operator equation (10)

$$
y_{W 1}=x^{-1} \exp \left(-n x^{2} / 4\right) M_{\frac{\mu-1}{2}, \frac{1}{2}}\left(n x^{2} / 2\right) ; \quad y_{W 2}=x^{-1} \exp \left(-n x^{2} / 4\right) W_{\frac{\mu-1}{2}, \frac{1}{2}}\left(n x^{2} / 2\right) \text {. }
$$

The negative rate of the dimensionless radius of $\left(x^{-1}\right)$ creates uncertainty at $\mathrm{x} \rightarrow 0$. You can get rid of this feature, if you replace a solution for FU Kummer function of the first and second type $M(a, b ; z), U(a, b ; z)$. For this we use depends on [7]

$$
\begin{gathered}
M_{k, s}(z)=z^{s+0,5} \exp (-z / 2) M(0,5+k+s, 1+2 s ; z) \\
W_{k, s}(z)=z^{s+0,5} \exp (-z / 2) U(0,5+k+s, 1+2 s ; z)
\end{gathered}
$$

Comparing the options in the FU and Kummer in functions, define the parameters of $a=(1+\mu) / 2, b=2$ and form a new shape to their functions (12a):

$$
y_{K 1}=\frac{n x}{2} \exp \left(-\frac{n x^{2}}{2}\right) M\left(\frac{3-\mu}{2}, 2 ; \frac{n x^{2}}{2}\right) ; \quad y_{K 2}=\frac{n x}{2} \exp \left(-\frac{n x^{2}}{2}\right) U\left(\frac{3-\mu}{2}, 2 ; \frac{n x^{2}}{2}\right) .
$$

Check equivalency conversion functions Kummer made in the program Maple 13 for values of parameters $\mu=0,3 ; n=4$ and shown in Figure 2 . 
$y K=2 \cdot x \cdot \exp \left(-2 \cdot x^{2}\right) \cdot \operatorname{Kummer} M\left(1.35,2,2 \cdot x^{2}\right)$;

$2 \cdot x \cdot e^{-2 x^{2}} \operatorname{Kummer} M\left(1.35,2,2 \cdot x^{2}\right) y K=2 \cdot x \cdot \exp \left(-2 \cdot x^{2}\right) \cdot \operatorname{Kummer} M\left(1.35,2,2 \cdot x^{2}\right)$;

$2 \cdot x \cdot e^{-2 x^{2}} \operatorname{Kummer} M\left(1.35,2,2 \cdot x^{2}\right)$

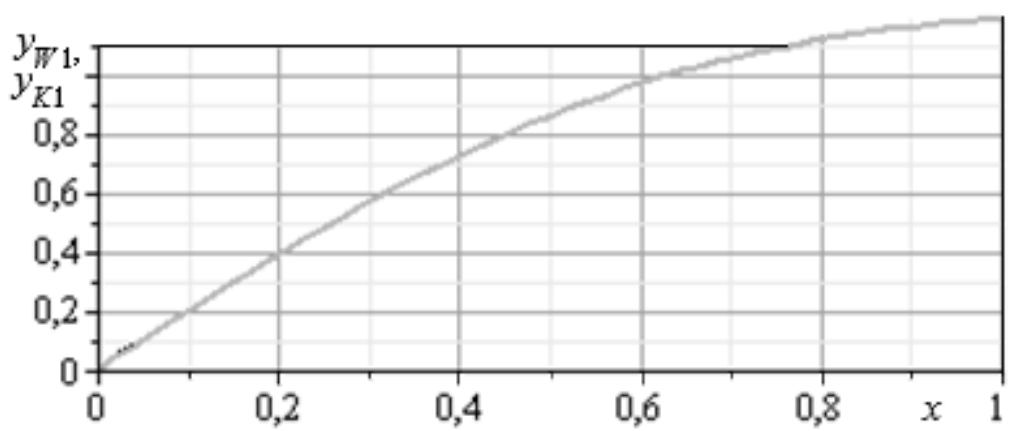

Figure 2. Graphs and functions $y_{W 1}$ i $y_{K 1}$ at values of $\mu=0,3 ; n=4$.

Full schedules overlap their functions (green curve corresponds to the solution of Kummer and function for all values of the argument $\mathrm{x}$ «covers» black, which corresponds to the solution with FU) indicates the correct replacement done. Additionally executed program Maple 13 difference calculation variables studied functions, not exceeding $\left|2 \cdot 10^{-9}\right|$, that is within the accuracy of calculations, Figure 3 .

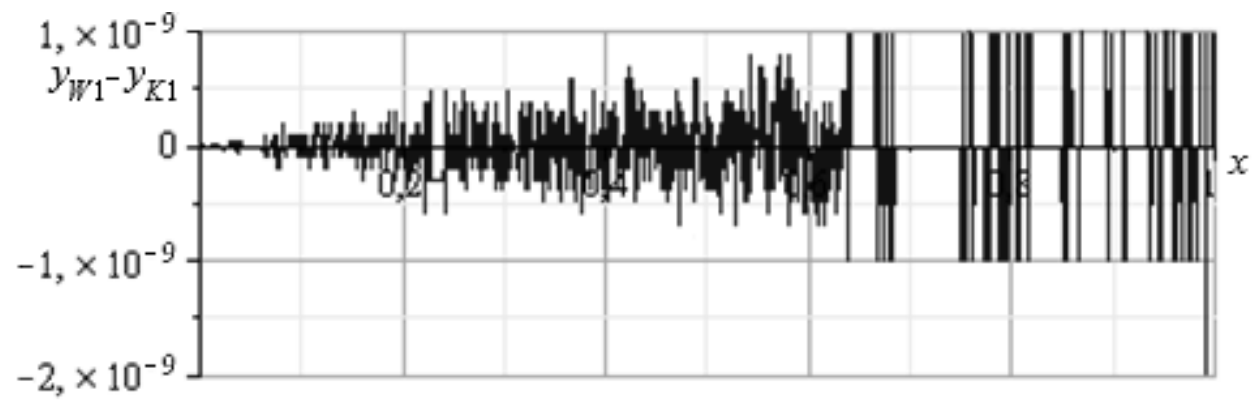

Figure 3. The difference $y_{w 1}$ functions and $y_{k 1}$

Note that the functions and Kummer Uittekera belong to a class of degenerate hypergeometric functions, they are used for the solutions to some problems of physics, astronomy and mechanics.

Custom functions (13) is the product of three functions, a power, exponential and Kummer, it's an argument to this problem lies in the range $(0 \ldots 1)$. The first two the factors in this range are limited quantities for research on the nature of those products should take into account the behavior of a third factor, functions Kummer range [11]. For clarity, this research program Maple 13 made their construction surface features (13), $y_{k 1}$ and $y_{k 2}$, variable in the range $0<x<1$ for values of Poisson's ratio $\mu=0,3$ setting $n=-6 \ldots 6$. 


$$
\begin{array}{ll}
\frac{1}{2} n \cdot x \cdot e^{-\frac{1}{2} n \cdot x^{2}} \operatorname{Kummer} M\left(1.35,2, \frac{1}{2} n \cdot x^{2}\right) ; & \frac{1}{2} n \cdot x \cdot e^{-\frac{1}{2} n \cdot x^{2}} \operatorname{Kummer} U\left(1.35,2, \frac{1}{2} n \cdot x^{2}\right) ; \\
\frac{1}{2} n \cdot x \cdot e^{-\frac{1}{2} n \cdot x^{2}} \operatorname{Kummer} M\left(1.35,2, \frac{1}{2} n \cdot x^{2}\right) ; & \frac{1}{2} n \cdot x \cdot e^{-\frac{1}{2} n \cdot x^{2}} \operatorname{Kummer} U\left(1.35,2, \frac{1}{2} n \cdot x^{2}\right) ;
\end{array}
$$

The result of the calculation is shown in Figure 4.

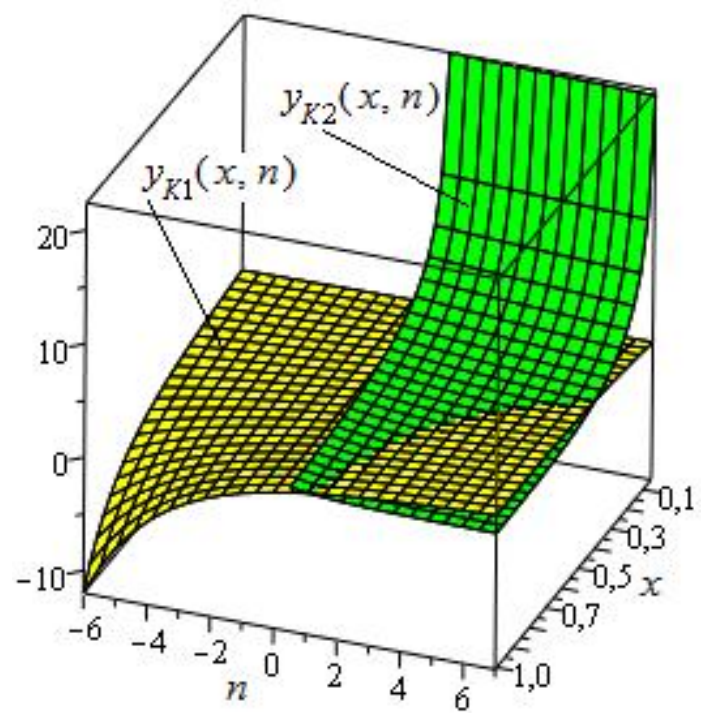

Figure 4. The surface features $y_{k 1}(x)$ and $y_{k 2}(x)$, depending on the parameter $n$

Figure 4. Illustrates important features received their functions:

(a) $-y_{k 1}(x)$ is limited in investigations (practically important) ranges argument $\mathrm{x}$ and the parameter n;

(b) - function $y_{k 2}(x)$ increases indefinitely at $x \rightarrow 0$;

(c) - function $y_{k 2}(x)$ for values of $n<0$ is not defined range of valid numbers, ie at negative values of $\mathrm{n}$ it is a function of a complex variable [7].

Solution of equation (10) using their own functions (13) has the form

$$
\phi(x)=\frac{n x}{2} \exp \left(-\frac{n x^{2}}{2}\right)\left[C_{1} M\left(\frac{3-\mu}{2}, 2 ; \frac{n x^{2}}{2}\right)+C_{2} U\left(\frac{3-\mu}{2}, 2 ; \frac{n x^{2}}{2}\right)\right]+\frac{p x}{(3-\mu) n} \exp \left(-\frac{n x^{2}}{2}\right)
$$

The above feature (b) own functions $y_{k 2}(x)$ at a value of $x=0$ is due to the nature of its factors, Kummer second order function $U(a, b ; z)$, with the argument $z=0,5 n x^{2}$. Angle $A C_{1}$ 


\section{- Processes and Equipment of Food Productions -}

normal to the curved middle surface at $x=0$ must be zero (see. Figure 1 ) and the condition $\varphi(0)=0$ execute accepting $C_{2}=0$. As a result, equation (14) takes the form

$$
\phi(x)=\left[C_{1} \frac{n}{2} F_{K 1}(x)+\frac{\bar{p}}{(3-\mu) n}\right] x \exp \left(-\frac{n x^{2}}{2}\right),
$$

where the function of the first kind Kummer taken designation

$$
M\left(\frac{3-\mu}{2}, 2 ; \frac{n x^{2}}{2}\right)=F_{K 1}(x)
$$

In equation (15) remained a constant $C_{1}$. For its definition should be used boundary conditions on the contour $x=R$.

\section{Conclusions}

A method for designing rational diametric sections of elements of machines and devices in the shape of round plates.

The mathematical software for the analytical method to minimize the mass of circular plates at a bend, which was first used functions and Kummer Uittekera belonging to the class of degenerate hypergeometric functions. Solution of the problem presented quite simple formulas.

The example design forms uniformly loaded circular cross section obpertoyi hinge plate analysis which showed the possibility of reducing weight by $40 \%$.

\section{References}

1. Kiciak A., Glinka G., Burns D. J. (2003), Calculation of Stress Intensity Factors and Crack Opening Displacements for Cracks Subjected to Complex Stress Fields, Journal of Pressure Vessel Technology, 125, pp. 260-266.

2. Gaschuk, P.M. (2002), Liniyni dinamichni sistemi $i$ zvichayni diferentsialni rivnyannya. Navch. Posibnyk, Lviv, «Ukrayinski tehnologiyi», 608.

3. Daschenko O.F., Homyak Yu.M., Naumenko E.O., Mozharenko O.M. (2016), Optimizatsiya formi dnischa zminnoyi tovschini dlya tsilyndrichnogo rezervuaru, «Teoriya ta praktika ratsionalnogo proektuvannya, vigotovlennya i ekspluatatsiyi mashinobudivnyh konstruktsiy» 5-a mizhnarodna nauk.-tehn. konf., pp. 23-25.

4. Koreneva E.B. (2009), Analiticheskie metodyi rascheta plastin peremennoy tolschinyi $i$ ih prakticheskie prilozheniya, Moskva, ASV, 238.

5. Towler Gavin, Ray Sinnott (2013), Chemical engineering design: principles, practice and economics of plant and process design (2nd ed.), Oxford: ButterworthHeinemann, ISBN 9780080966595.

6. Vinokurov V.A., Kurkin S.A., Nikolaev G.A. (1996), Svarnyie konstruktsii. Mehanika razrusheniya i kriterii rabotosposobnosti, Moskva, Mashinostroenie, 576. 
7. Korn Granino Arthur, Korn Theresa, (2000), Mathematical handbook for scientists and engineers : definitions, theorems, and formulas for reference and review, Courier Dover Publications, p. 169, ISBN 0-486-41147-8.

8. Timoshenko S.P., Voynovskiy-Kriger S. (1966), Plastinki i obolochki. Moskva, Nauka, 636.

9. Homyak Yu.M., Tshigam G.Zh. (2015), Rozvyazok zadachi viginu krugloyi plastini zminnoyi tovschini z vikoristannyam funktsiy Uittekera, Modelirovanie v prikladnyih nauch. issledovaniyah, Odesa, 23, 79-80.

10. Saveleva O.S., Homyak Yu.M., Stanovskaya I.I., Toropenko A.V., Naumenko E.A. (2016), Optimizatsiya ravnonapryazhenyih konstruktsiy tsilindricheskih rezervuarov v SAPR, Vostochno-evropeyskiy zhurnal peredovyih tehnologiy, 6/7(84), pp. 10-16.

11. Daalhuis Adri B. Olde, Olver Frank W.J., Lozier Daniel M., Boisvert Ronald, Clark Charles W. (2010), Confluent hypergeometric function, Handbook of Mathematical Functions, Cambridge University Press.

12. Brar G.S., Hari Y., Williams D.K. (2009), Fourier Series Analysis of a Cylindrical Pressure Vessel Subjected to External Pressure, ASME 2009 Pressure Vessels and Piping Conference, New York.

13. Brar G.S. (2009), Buckling Load Predictions in Pressure Vessels Utilizing Monte Carlo Method, Ph.D. Thesis, University of North Carolina at Charlotte, USA.

14. Elishakoff I., Li Y., Starnes, J.H. (2001), Non-Classical Problems in the Theory of Elastic Stability, Cambridge University Press, Cambridge, UK. 